\title{
Monetary Policy Rules with PID Control Features: Evidence from the UK, USA and EU
}

\author{
David Shepherd* \\ david.shepherd@imperial.ac.uk \\ Rebeca I. Munoz Torres** \\ R.Munoztorres@westminster.ac.uk \\ George Saridakis+ \\ G.Saridakis@kent.ac.uk \\ *Imperial College \\ **Westminster Business School \\ + Kent Business School
}

\begin{abstract}
This paper considers the extent to which the monetary policy operations of three major central banks can be regarded as an application of Proportional-Integral-Derivative (PID) control rules. The paper outlines the general PID framework and estimates a series of dynamic models to identify how interest rate policy adjustments are affected by the rate of inflation and the level of macroeconomic activity. The paper examines data for the UK, the USA and the Eurozone. The results suggest that the PID rules can provide a useful theoretical and empirical framework for estimating central bank responses to the inflation and macroeconomic activity variables by improving the explanatory power of the Taylor rule model and determining the effect of the parameters.
\end{abstract}

. Keywords: Monetary Policy Rules; Taylor Rules; Feedback Control; PID Control Rules.

JEL Classification Codes: E52; E58 


\section{Introduction}

There is a now a huge literature devoted to the analysis of monetary policy rules and the circumstances in which different rules can be regarded as optimal, in the sense that they generate outcomes that are consistent with or maximize some objective function that a central bank may use to guide policy decision-making. There are two broad themes in this literature: first, the identification of optimal rules derived from explicit choice-theoretic models of the determinants of real GDP and inflation; secondly, the identification of practical rules that can be used to guide policy when there is incomplete knowledge or uncertainty about the structure of the underlying model.

In relation to the first theme, recent research has focused on the optimality of alternative monetary policy rules in the context of stochastic dynamic general equilibrium models, which allow for both rational expectations and the possibility of rigidities (see for example, Woodford 2013; Christiano et al., 2011; Mishkin 2007; Kobayashi, 2005; Taylor, 1999). A key advantage of this approach is that it implies the derivation of consistent rules, which in principle incorporate all of the relevant information suggested by the model. However, the validity of any such rules is conditional on the validity of the model from which they are derived (Orphanides and Williams, 2008). Furthermore, as discussed in Taylor and Williams (2011), model simulations suggest that the advantages of fully modelconsistent rules are in practice small in comparison to simple monetary policy rules derived from less formal models ${ }^{1}$.

Turning to the second theme, which focuses on the identification of practical policy rules, although it has a long history, the current literature really begins with the seminal work of Taylor (1993) and much of the discussion of monetary policy rules is couched in terms of the analysis of "Taylor Rules". Representative examples of work in this area include Ball and

\footnotetext{
${ }^{1}$ See for example, William (2003); Levin et al. (2003); and Schmitt-Grohe and Uribe (2007).
} 
Tchaidze (2002) and Clarida et al. (2000) for the United States; Adam et al. (2005) and Nelson (2001) for the United Kingdom; and Carstensen (2006) and Hayo and Hofmann (2006) for the European Union. Most studies are based on modified versions of the original Taylor rule, with additional explanatory variables or generalisations of the functional form.

This paper considers the specification of Taylor-type rules for monetary policy and their relationship to feedback control rules of the kind developed for engineering and physical systems. We argue that there is a strong parallel between the problems faced by policymakers when setting interest rates and those faced by control system engineers. This similarity has long been recognised in the monetary policy literature, but there have been surprisingly few attempts to incorporate these control system ideas explicitly; a notable exception however, is Hawkins et al. (2015), who examine US monetary policy decisions over the period 1987-1992 with the aid of an explicit Proportional-Integral-Derivative (PID) control model. In both cases, the aim is to adjust an input to the system in the hope of achieving an outcome (output) which is as close as possible to a specified target value; but in both cases there is a degree of uncertainty about the system response, which implies an output error, measured as the divergence between the target and actual outcome.

The degree of error (or uncertainty) attached to the system output may be greater for the central banker than for the engineer, because engineering systems are usually better understood than are economic systems ${ }^{2}$. Nevertheless, for many engineering systems, such as a process plant, there are may still be significant uncertainties about the system responses ${ }^{3}$ and some form of feedback control is typically required to minimize the output errors. For such systems, it has been shown that a particularly robust set of control operations can be

\footnotetext{
${ }^{2}$ An interesting discussion of model uncertainty and the relevance of constructs such as the output gap for monetary policy can be found in the interchanges between members of the UK Monetary Policy Committee and the House of Lords Economic Affairs Committee (House of Lords, 2005). The implications of model uncertainty are also discussed in King (2012).

${ }^{3}$ Such uncertainties can arise partly because of ambiguities in the physics of the system and partly because of performance variations arising from factors related to design, materials, and construction qualities.
} 
derived via the application of PID control rules to handle present errors, correct accumulated past errors and predict future errors (see Bennett, 1993) ${ }^{4}$.

Our objective is to assess whether the policy operations of three important Central Banks can usefully be described with the aid of engineering-type control rules. Specifically, we are inspired by the work of Hawkins et al. (2015) and use the PID control algorithms to assess the impact of inflation and macroeconomic activity on the interest rate decisions of the US Federal Reserve, the Bank of England, and the European Central Bank. A distinctive feature of this approach is that the underlying dynamic equations of the model do not need to be fully known to derive optimal policy rules.

The remainder of the paper has the following structure. Section 2 discusses the key features of the Taylor rule and its relation to PID-based control rules. Section 3 outlines the model specification used in the paper. Section 4 discusses the data. Section 5 presents the statistical analysis and discusses the results. The final section provides a summary of the paper with concluding comments.

\section{Background}

\subsection{Taylor rules and monetary policy}

The literature on monetary policy rules has been dominated over recent years by the development of variations of the Taylor rule. The original rule suggested by Taylor (1993) has the central bank interest rate as the policy variable which is adjusted according to deviations between the actual and target values for the objective variables, which are typically inflation $\pi_{t}$ and real output $y_{t}$ or inflation and the rate of unemployment $u_{t}$. In some variations, the policy rate $i_{t}$ is set with reference to an equilibrium (natural) real rate $r_{t}^{*}$ and the equation guiding the policy decision is:

$$
i_{t}=r_{t}^{*}+\alpha_{1} \cdot p_{t}+\alpha_{2} \cdot m_{t}
$$

\footnotetext{
${ }^{4}$ A comprehensive discussion of PID control features can be found in Astrom and Murray (2008).
} 
where $p_{t}$ represents the deviation of inflation from its target, $p_{t}=\left(\pi_{t}-\pi_{t}^{*}\right)$, and $m_{t}$ represents either the deviation of output from its potential level, $m_{y, t}=\left(y_{t}-y_{t}^{*}\right)$ or the deviation of unemployment from its equilibrium (natural) rate, $m_{u, t}=\left(u_{t}-u_{t}^{*}\right)$. However, in view of the difficulty in determining the value of the equilibrium real interest rate, the model is more typically expressed with the lagged policy variable as the reference point for the current policy decision ${ }^{5}$ :

$$
i_{t}=i_{t-1}+\alpha_{1} \cdot p_{t}+\alpha_{2} \cdot m_{t}
$$

In this formulation the policy decision amounts to a decision about whether to raise or lower the policy rate from its current level in the light of current information about the deviations of inflation and output from their target or equilibrium levels (e.g. if the net gap is positive the rate should be raised) :

$$
\Delta i_{t}=\alpha_{1} \cdot p_{t}+\alpha_{2} \cdot m_{t}
$$

In practice, when the above equations are used to model historical policy actions, it is common to incorporate amendments to allow for the possibility of policy inertia (typically expressed as partial adjustment, to reflect caution on the part of policy makers) and/or asymmetric adjustment (differing parameter values for positive and negative values of the deviation terms, to reflect for example a greater aversion to above-target inflation, compared to below-target inflation).

The equations can of course be modified further, for example by incorporating expected or forecast deviations of inflation from its target, rather than current deviations, or by introducing alternative indicators of macroeconomic activity, such as the unemployment rate, and, for some very open economies, the exchange rate. When such modifications are introduced, however, it is important to ensure that the rule remains consistent with the underlying analysis and the central bank's specified target. For example, if the central bank is

\footnotetext{
${ }^{5}$ A theoretical rationale for the inclusion of the lagged interest rate can be found in Woodford (2003).
} 
concerned only with inflation, and the decision rule incorporates the deviation of forecast inflation from its target, rather than the current period deviation, it is arguable that the indicator of macroeconomic activity is then redundant, because the inflation forecast should already include the impact of current activity on price movements.

While the different variations of the Taylor rule are or should be consistent with underlying macroeconomic theory, particularly with respect to the relationship between inflation and macroeconomic activity and the impact of the policy variable, for the most part the rules are not derived from an optimizing procedure applied to a complete formal model of the macroeconomic system. In this respect they can be regarded as an attempt to use efficient practical rules to guide policy decisions in an environment in which there is broad understanding of the inter-relationships within the macroeconomic system, but significant uncertainty about the precise nature of those relationships and the impact of changes in the policy variable. Expressed in these terms, the Taylor rules are effectively variants of the feedback rules developed for the control of engineering systems (for further discussion, see Hawkins et al., 2015).

\subsection{The PID control rules}

Following the control theory literature, for the case of a continuous time-invariant system, where the problem is to vary a control input with reference to a target output, the optimal controllers are based on a combination of proportional, integral and derivative control. Below we summarise the elements of the PID controller.

A proportional $(\mathrm{P})$ controller adjusts the control input $r_{t}$ in proportion to the difference between the desired and actual output, which is the system error $e_{t}$ :

$$
r_{t}=K_{P} \cdot e_{t}
$$


This controller most closely resembles the original Taylor rule specification and the logic behind it is straightforward, with offsetting input adjustments applied to counter the current or most recent deviation from the target.

Additional information from the past behaviour of the system can be incorporated with a proportional plus integral (PI) controller, which allows for the input to be adjusted in proportion to the current system error and the integral of past errors:

$$
r_{t}=K_{P} \cdot e_{t}+K_{I} \cdot \int_{o}^{t} e_{t} d_{t}
$$

In this case, the adjustment to counter the current deviation is supplemented by an additional adjustment which is intended to counter any systematic bias in the operation of the system, revealed by the accumulation of past errors (typically the development of a persistent undershoot or overshoot of the output relative to its target). As we discuss later, when viewed in terms of the Taylor rules, the use of the PI controller effectively provides a justification for the inclusion of a dynamic lag structure in the control rule.

Finally, an allowance for expectations about the future behaviour of the gaps can be incorporated via a proportional plus derivative (PD) controller, which adjusts the input in proportion to the current system error and the time derivative of the current error:

$$
r_{t}=K_{P} \cdot e_{t}+K_{D} \cdot \frac{d e_{t}}{d t}
$$

The logic here is that the derivative of the error provides information about the most recent direction of the change in the system error and is equivalent to a proxy forecast of the error direction, which indicates whether the proportional adjustment to the error should be altered to allow for the fact that it is expected to rise or fall.

The most general form of the controller combines all three terms in a PID controller:

$$
r_{t}=K_{P} \cdot e_{t}+K_{I} \cdot \int_{o}^{t} e_{t} d_{t}+K_{D} \cdot \frac{d e_{t}}{d_{t}}
$$

This controller utilizes the full range of information about the current, past and expected future behaviour of the system. In engineering applications, the PID controller is generally 
regarded as the most useful of the various control alternatives, although in many instances the derivative term is omitted, leaving the PI controller as the preferred choice, on the grounds that the first difference procedure effectively introduces a form of filtering that emphasises high frequency variations, which can suggest frequent input adjustments that do not usefully contribute to the achievement of the target output and may indeed induce instability ${ }^{6}$.

\subsection{Applying PID rules to the estimation of Taylor rules}

In many practical applications, including the monetary policy context we are concerned with, the required control information is not available in continuous time and it is necessary to apply the controller in a discrete-time form (i.e. the economic variables are measured on a periodic basis). The most direct way of doing this is simply to replace the continuous-time measures with their discreet time counterparts. Assuming unit time intervals, and measuring the discreet-time error difference $\Delta e_{t}$ as the back-difference, $\left(e_{t}-e_{t-1}\right)$, the PID controller (equation 7) can be expressed as:

$$
r_{t}=K_{P} \cdot e_{t}+K_{I} \cdot \sum_{0}^{t} e_{t}+K_{D} \cdot \Delta e_{t}
$$

Equation (8) is often referred to as the 'positional algorithm' because it calculates the control action from an initial position at time $t=0$. In many applications, the controller is applied in an amended difference form. Subtracting $r_{t-1}$ from both sides of (8) gives:

$r_{t}-r_{t-1}=K_{P} \cdot\left(e_{t}-e_{t-1}\right)+K_{I} \cdot\left(\sum_{0}^{t} e_{t}-\sum_{0}^{t-1} e_{t-1}\right)+K_{D} \cdot\left(\Delta e_{t}-\Delta e_{t-1}\right)$

In this case, the integral terms cancel out to leave a term in the current error and we have:

$r_{t}-r_{t-1}=K_{P} \cdot\left(e_{t}-e_{t-1}\right)+K_{I} \cdot e_{t}+K_{D} \cdot\left(e_{t}-e_{t-1}\right)-K_{D} \cdot\left(e_{t-1}-e_{t-2}\right)$

And after re-arranging:

$$
r_{t}=r_{t-1}+k_{1} \cdot e_{t}+k_{2} \cdot e_{t-1}+k_{3} \cdot e_{t-2}
$$

\footnotetext{
${ }^{6}$ In practice, this can be countered by the application of low frequency filtering, to retain some of the (trend) error forecast information contained in the first difference term, while removing the high frequency noise variation.
} 
with $k_{1}=K_{P}+K_{I}+K_{D}, k_{2}=-\left[K_{P}+2 K_{D}\right], k_{3}=K_{D}$

In the present context we are concerned with monetary policy decisions in which the central bank decides whether to alter a reference interest rate in the light of its judgement about the deviation of inflation from the target rate and deviations of output or unemployment from their equilibrium levels (either because the bank has explicit targets with respect to output or unemployment or because of an assessment about how they are likely to affect future inflation). To this end, we consider the applicability of the models described by equations (8) and (11).

\section{Model specification}

Our objective is to determine whether central bank monetary policy operations can usefully be described with the aid of the PID control algorithms discussed above. We examine the interest rate policy decisions of three major central banks: the Bank of England (BoE), the Federal Reserve (FED), and the European Central Bank (ECB). Although the analysis can be viewed in part as an attempt to identify relevant variations of the Taylor-type rules, a distinctive feature of our approach is that it also provides a formal justification for utilizing a dynamic model structure in the estimation of those rules. Following Hawkins et al. (2015) and assuming for the moment that the Central Bank is concerned with deviations of inflation and macroeconomic activity from their target levels, as in equation (2), and utilising the structure of equation (11), the implied interest rate adjustment equation for the PDI form is:

$i_{t}=i_{t-1}+k_{p 1} \cdot p_{t}+k_{p 2} \cdot p_{t-1}+k_{p 3} \cdot p_{t-2}+k_{m 1} \cdot m_{t}+k_{m 2} \cdot m_{t-1}+k_{m 3} \cdot m_{t-2}$

Applied as a regression model, equation (12) is simply a representation of the linear dynamic model, with specific restrictions imposed on the lag structure and the parameter value of the lagged dependent variable. It is important to note, however, that the derivation of this structure comes from well-established PID control principles rather than the ad hoc 
extension of an otherwise static model. In the empirical work that follows, we use equations (12) to assess the impact of the inflation and macroeconomic activity variables on the interest rate policy adjustments of the central banks. For comparison purposes, we also follow Hawkins et al. (2015) and estimate the model using a PI-rule by dropping the derivative term and expressing equation (12) in the following form: ${ }^{7}$

$$
i_{t}=i_{t-1}+k_{p 1} \cdot p_{t}+k_{p 2} \cdot p_{t-1}+k_{m 1} \cdot m_{t}+k_{m 2} \cdot m_{t-1}
$$

Our statistical analysis covers only the period up to the end of 2007, when normal monetary policy rules were in operation.

\section{Data}

Our empirical analysis is based on an examination of quarterly data for the UK, the USA and the Eurozone. For the US the dataset covers the period 1990Q1-2007Q4 whereas for UK and EU we consider the time periods 1997Q1-2007Q4 and 1999Q1-2007Q4, respectively ${ }^{8}$. For the latter two countries, the starting date for the analysis is chosen as the time when the Euro came into existence, but it also roughly coincides with the passing of the Bank of England Act of 1998, which granted central bank independence in monetary policy decision-making in the UK, and the period as a whole is generally one in which explicit inflation targets for monetary policy were in operation.

The empirical model assumes that movements in the policy rate $i_{t}$ are determined by the deviation $p_{t}$ of the rate of inflation from its target value and the deviation $m_{t}$ of macroeconomic activity from its sustainable equilibrium level. In practice it is unclear

\footnotetext{
${ }^{7}$ Or $\Delta r_{t}=k_{1} \cdot e_{t}+k_{2} \cdot e_{t-1}+k_{3} \cdot e_{t-2}$, which is often referred to as 'velocity algorithm' because it calculates the control action as the change in the direction of the input from its previous position (see Levin et al., 2003).

${ }^{8}$ The data was obtained from the Federal Reserve Economic Data Base (FRED) and the official statistics provided by the Bank of England and ECB websites. Although data is available beyond 2007, we impose 2007Q4 as the end date of the analysis to avoid the distorting impact of the financial crisis and the zero-bound wind-up problem.
} 
whether the state of macroeconomic activity is best represented with an output or unemployment variable and both are considered in the empirical analysis. The output measure $m_{y, t}$ is the deviation of real GDP from its trend level and the unemployment measure, $m_{u, t}$ is similarly the deviation of the unemployment rate from its trend rate. The specific measures of the variables are as follows.

The policy rate $i_{t}$ is measured as the Federal Funds Rate for the US, the Bank of England Official Rate for the UK, and the European Central Bank Refinance Rate for the Eurozone.

The inflation deviation term $p_{t}$ is measured as the numerical difference between the actual and target inflation rates for each country, using the Eurostat HICP series for the Eurozone and the FRED CPI series for the US and the UK. In accord with official policy statements, the Bank of England's inflation target is set as 2.5\% for the 1999 to 2003 period and $2 \%$ afterwards. The ECB has defined its inflation objective as a rate of inflation below but close to $2 \%$ and for estimation purposes we interpret this as an inflation target of $1.9 \%$. In the case of the FED, although there is no official inflation target, the Federal Reserve Act of 1913 does specify the objective of "price stability" (as well as "high employment") and we follow the common view that over recent years this can be regarded as an implicit target of $2 \%$, often referred to as a $2 \%$ threshold $^{9}$.

The output variable $m_{y, t}$ is measured for the UK and EU as the percentage deviation of seasonally adjusted real GDP from the Hodrick-Prescott (HP) trend, with the smoothing parameter set at the conventional 1600 value for quarterly data ${ }^{10}$. For the US, however, we

\footnotetext{
${ }^{9}$ See for example Goodfriend (2007).

${ }^{10}$ When the smoothing parameter is set at 1600 , the HP filter effectively identifies the cyclical deviations of GDP as fluctuations up to a period of around 8 or so years. It is possible to vary the cycle length by changing the smoothing parameter or by utilizing alternative high-pass or band-pass filters, such as the Butterworth filter (see for example Pollock, 2000; Shepherd and Dixon, 2008).
} 
the potential output series published by the FRED ${ }^{11}$. Finally, the unemployment variable $m_{u, t}$ is measured as the percentage deviation of the civilian unemployment rate from its HP trend rate for all countries. To facilitate the interpretation of the results, we measure these variables in percentage terms.

\section{Statistical Analysis and Results}

Before estimating the model, it is helpful to discuss briefly the properties of the data. The output and unemployment variables are measured as deviations from the HP trend and are stationary by construction, but the same is not true for the interest rate series and the deviation of inflation from its target value. As a preliminary matter, we applied unit root tests to determine the order of integration of these series for each country using the Phillips and Perron (1988) test.

The results suggest that the inflation deviation term is stationary for the estimated sample period and selected countries. We find, however, that that the policy rate $i_{t}$ can be regarded as non-stationary over the sample period for each country, but it becomes stationary after first differencing. From a theoretical perspective, however, the underlying assumption of the Taylor rule is that monetary policy steers the interest rate conditional on the economic environment. Hence, there is probably a strong theoretical base to assume that the interest rate is stationary. In line with this argument, advanced unit root tests such as the ones proposed by Zivot and Andrews (1992) ${ }^{12}$ and Clemente et al. (1998) reject the null

\footnotetext{
${ }^{11}$ However, the GDP smoothing approach using an HP filter is strongly correlated with the potential output published by FRED $(0.998 * * *)$. *** Significant at the $1 \%$ level.

${ }^{12}$ The minimum- $t$ statistics are -5.960 (UK), -5.547 (US) and -5.188 (EU). The critical values for the minimum$t$ are given by Zivot and Andrews (1992); 1\%: -5.57 5\%: -5.08 10\%: -4.82 . To avoid detecting breaks closer to the two ends of the sample the data was trimmed at $10 \%$. For the UK and EU, we detect possible trend breaks in 2003Q1 and 2005Q1; for the USA, a possible trend break occurs in 2001Q1. These dates closely coincide with the start/end of recession in USA and labour market reforms in Europe. Clemente et al. (1988) provides similar results regarding the order of integration of the series (the estimated $t$-statics are $-3.905,-12.706$ and -4.818 ; this is compared against the 5\% critical value, -3.560). However, this test suggests potential beaks in 2002Q1 for UK, 2003Q4 for EU, and 2002Q4 for USA, although only the former one is found to be statistically significant at the 5\% level. For the purpose of this paper, however, it is important to note that both tests indicate that the policy variable is probably stationary.
} 
hypothesis of a unit root in the series. So we will estimate the model using the level of interest rate and in recognition of the fact that the control equation can be regarded as a restricted version of the linear dynamic model, we allow a lagged interest rate to enter the monetary policy rule.

Following Hawkins et al. (2015) we estimate the model using Ordinary Least Squares (OLS) approach with heteroskedasticity and autocorrelation-consistent (HAC) statistics to deal with problems of serially correlated errors and conditional heteroscedasticity of the regression disturbances. Our empirical analysis is based on the estimation of a set of three models: (i) the Taylor-rule model (equation 2); (ii) The PI-rule model (equation 13); and (iii) the PID model (equation 12). For each of the unrestricted models, the most likely model order was identified using the Akaike Information Criterion (AIC) ${ }^{13}$. Tables 1-3 below present the results for the UK, US and Eurozone respectively. Each table reports the parameter estimates for the identified model structures (with standard errors). The tables also report the adjusted $\mathrm{R}^{2}$, the Shapiro -Wilk W test for normality and the RESET test for the suitability of the imposed linear functional form.

The other statistical matter of potentially relevance is the possibility of collinearity between the inflation and macroeconomic activity regressors, which could affect the reliability of the parameter estimates. A preliminary correlation analysis of the variables indicates that there is a small and generally insignificant correlation over the sample period between the inflation and output deviation variables for the UK and the US and between the

\footnotetext{
${ }^{13}$ We also estimate more general models without lagged values of the dependent variables and with dummy variables incorporated, to allow different parameter values for above target and below target deviations. The latter objective was to determine whether the policy preferences of the central banks are symmetric with respect to deviations of inflation and macroeconomic activity from their target values, or whether they exhibit, for example, a greater aversion to above-target than to below-target inflation. However, since the exclusion of the lagged dependent variable did not provide further insights and the coefficients of the dummy variables were generally statistically insignificant the results for these models are not reported.
} 
inflation and unemployment deviations for the $\mathrm{US}^{14}$. Also the variance inflation diagnostics reveal that the mean variance inflation factor (VIF) across all models lie between 1 and 1.07. Hence the results suggest that the results are not distorted by multicollinearity.

\subsection{Estimation results for the UK}

The results for the UK are presented in Table 1. Across the different models and specifications presented here (Models 1A-6A), we find that the parameter value of the lagged dependent variable (or smoothing parameter) is highly statistically significant, with a probability value ranging from 0.919 to 0.966 . Its average value in all specifications implies that for a given change in the interest rate, the proportion reflected in the same quarter is quite small, presumably revealing a concern of the authorities to adjust interest rates by small steps.

When the Taylor-type rule model is used (Models 1A and 4A) the estimates suggest a significant association between adjustments in the policy rate and the deviation of inflation from target. For both models, the inflation gap parameters ( 0.164 and 0.152 , respectively) are positive and statistically significant at $5 \%$ level, suggesting that the BoE policy rate rises when inflation moves above target. Similarly, the BoE seems to respond to the output indicator (see Model 1A) by increasing interest rates when output is above its potential level (a one percentage point increase in output gap increases the policy rate by 0.223 percentage points). In contrast, the parameter value for the unemployment indicator (see Model 4A) is not statistically significant.

As discussed earlier, the PI policy rule adds one-period lags for the inflation gap and the corresponding macroeconomic activity indicators (i.e. output gap and unemployment gap, respectively). The results presented in Models 2A and 5A, however, are broadly similar to the estimation results obtained from the Taylor-type rule. Specifically, the contemporaneous

\footnotetext{
${ }^{14}$ The contemporaneous correlations between the output gap and inflation deviation are $-0.081,0.015$ and 0.003 for the UK, US and the EU respectively, and $0.176,-0.248^{* *}$ and -0.099 for the inflation and unemployment deviations. **Significant at the $5 \%$ level.
} 
coefficient associated with deviations of inflation from its annual target has the expected sign and the magnitude and statistical significance remain unchanged. The F-test does not reject the null hypothesis of the equality of the coefficients in the two regressions $(F$-value $=0.01$ and $p$-value $=0.917)$. However, the coefficient of the lagged parameter is not statistically significant. Similarly when considering the response of the central bank to output fluctuations around its potential level (see Model 2A) the coefficient of the lagged variable in the estimation is found to be individually and jointly $(F$-value $=0.12$ and $p$-value $=0.891)$ statistically insignificant; however, its contemporaneous coefficient (0.245) remains stable, and is positive and statistically significant at the 5\% level. Finally, if we look at the estimates which use the unemployment gap in the monetary policy specification (Model 5A) the initial change in the policy rate is subsequently reversed and the sum of the contemporaneous and lagged effects is equal to zero $(F$-value $=0.25$ and $p$-value $=0.622)$. This suggests that the impact of this macroeconomic indicator is negligible when interest rates are set by the central bank. Overall, the results suggest that monetary policy in the UK responds mainly to current deviations of inflation from its target and the output gap, but and to lesser extent to deviations of unemployment from its trend value, which suggests that monetary policy has been consistent with inflation targeting principles.

Adding a two-period lag structure in the model to correspond to the full PID rule (see equation 13) does not improve the explanatory power of the regression model. The results presented in Models 3A and 6A show that none of the contemporaneous inflation gap coefficients are statistically different from zero when the first two lags of inflation gap included in the specification. However, the coefficient on the output gap (see Model 3A) remains statistically significant for the current deviation of output from its trend. Finally, responses to changes in the unemployment gap (see Model 6A) seem to be statistically significant for the second lagged parameter, but the effect is positive and relatively small in 
magnitude. The contemporaneous and lagged unemployment gap coefficients are jointly found to be statistically significant $(\mathrm{F}$-value $=8.07$ and $\mathrm{p}$-value $=0.000)$, but the cumulative effect is found to be zero $(F$-value $=2.66$ and $p$-value $=0.112)$.

Looking across the model set for the UK, it appears that the PI and PID control equations do not suggest that the dynamic effects of the inflation and macroeconomic activity variables are significant. The Akaike information criterion suggests that the Taylor rule outperforms both the PI and PID rules when the output gap is considered in the model, and the likelihood ratio (LR) test for model selection yields same conclusions ${ }^{15}$. When the unemployment gap is included instead, the PI and PID models outperform the Taylor-rule, but the trade-off between PI and PID is perhaps less pronounced despite the fact that the model selection criteria favours the latter.

[Table 1 about here]

\subsection{Estimation results for the USA}

We now turn to the United States, these results are presented in Table 2. As with the UK, the lagged interest rate variable is found to carry a significant and large coefficient (which is found to vary between 0.810 and 0.922 ) in the estimated policy rules for the USA (see also Clarida et al, 2000; Kozicki, 1999). The smoothing parameters for Models 1B-6B, however, suggest a higher degree of inertia in the policy adjustment process when considering the output gap rather than the unemployment gap in the specification.

The Taylor-type rule model with the output deviation term (Model 1B) suggests that adjustments in the policy rate are influenced by deviations of inflation from its target and the output gap. The Federal Reserve Bank (Fed), however, seems not to respond aggressively to output deviations, although the coefficient of output gap (0.092) has a greater statistical

\footnotetext{
${ }^{15}$ Under normality, OLS estimates, which by definition minimize a sum of squared residuals, are also maximum likelihood estimates. Comparing Model 2A with Model 1A, we obtain $x^{2}(2)=0.07$ ( $p$-value $=0.965$ ). Similarly, Model 1A is selected over Model 3A $\left(x^{2}(4)=1.66\right.$ and $p$-value $\left.=0.798\right)$.
} 
significance than the inflation gap (0.206). ${ }^{16}$ Interestingly, the results from the estimation using unemployment (Model 4B) rather than output as an indicator of macroeconomic activity indicate that adjustments in interest rate are determined by deviations of unemployment from its trend value only $(-0.043)$. In this specification, the coefficient of the inflation gap loses its statistical significance at the $10 \%$ level.

The second set of estimations (Models 2B and 5B), which include a one period lagged value for the two macroeconomic activity variables, support previous findings from the Taylor-type model when using the output gap as indicator. The Fed seems to react mainly to current deviations of inflation and the output gap rather than to lagged deviations. However, adding the lag terms improves the explanatory power of the model, and alters the magnitude and significance levels of the contemporaneous coefficients. In particular the PI rule nearly doubles the output gap coefficient, but the statistical significance reduces at the $5 \%$ level $^{17}$.

Turning to the estimation results that include unemployment deviations (Model 5B) we observe a significant rise in the policy rate when current inflation moves above the trend. The response to lagged inflation is positive but statistically insignificant. For unemployment deviations, there is a significant policy response to current changes followed with a lag by an opposite response. The sum of the parameter values indicates an overall reduction of the policy rate when unemployment is above its trend value, which is the expected response from policy makers. We test the restriction that the contemporaneous and lagged unemployment gap coefficients sum to the coefficient reported in the Taylor model. The test does not reject the null hypothesis $(F$-value $=1.86$ and $p$-value $=0.177)$ and hence implies that the effect of

\footnotetext{
${ }^{16}$ We also estimate the model without the lagged interest rate term to contrast the estimates with the ones that appeared in column 1 of Table 2 of Hawkins et al (2015). We find inflation gap and output gap responses of 1.104 and 0.349, respectively. These estimates are closer to the ones reported by Hawkins et al. (2015), and Taylor (1993). However, allowing for interest rate smoothing in the specification increases the (adjusted) Rsquared by 0.819 . Also, the LR-test between the two models confirms that the model with the lagged interest rate term has more explanatory power $\left(\operatorname{LR} x^{2}(1)=198.42\right.$; statistically significant at the $1 \%$ level). We therefore proceed with our analysis including the lagged interest rate as an explanatory variable in the PI and PID models. ${ }^{17}$ However, the F-test does not reject the null hypothesis of the equality of the coefficients in the two regressions $(F$-value $=0.58$ and $p$-value $=0.451)$.
} 
unemployment deviation are similar in magnitude in the PI model. We also find that the coefficients of lagged inflation and unemployment gaps to be jointly statistically significant $(F$-value $=4.93$ and $p$-value $=0.010)$.

A third set of estimations incorporates the PID model with two-period lagged values of the explanatory variables. Model 3B suggests that the central bank in the US reacts mainly in response to inflationary pressures. In particular, no significant impact is identified from the current and second lagged inflation terms, but from the lagged inflation instead. For the output deviations terms, the parameters indicate an increase in the policy rate when output is above its trend value followed by a decreased adjustment in interest rates after two periods. We test the restriction that the two coefficients sum to zero and find that the null hypothesis cannot be rejected $(F$-value $=0.04$ and $p$-value $=0.846)$. Overall, the results suggest that monetary policy in the US is committed effectively to the pursuit price stability. Similarly, in Model 6B the coefficients of inflation deviations from its target have all the expected values, but it is the response to current deviations that is statistically significant. The magnitude of the coefficient, however, is smaller when compared to the one reported in PI model, and the difference is found to be statistically insignificant $(F$-value $=0.84$ and $p$-value $=0.364)$. The unemployment deviation term is significant for the current and two-period lagged value but with opposite signs suggesting that the initial change is subsequently reversed. The overall effect, however, remains negative and similar to the one found in Taylor/PI model ( $F$ value $=0.31$ and $p$-value $=0.579)$.

Comparing the Taylor rule model with the PI and PID models, we find that the latter models are favoured from the Akaike information criterion. Also there is a modest improvement associated with the move from PI to PID. The LR-test also reveals that the PID 
models (i.e. Model 3B and Model 6B) are more appropriate than the Taylor-rule (Model 1B and Model 4B) or PI rule (Model 2B and 5B). ${ }^{18}$

[Table 2 about here]

\subsection{Estimation results for the Eurozone}

In Table 3 we present the results for the Eurozone. The parameter of the lagged dependent variable using the output gap suggests a more gradual adjustment in interest rates than the one observed from the Fed and BoE. The effect of this partial adjustment is, however, smaller when the unemployment gap instead of the output gap is included in the specification, with the value of the parameter between 0.710 and 0.845 .

For the Taylor-rule equation incorporating the output deviation indicator (Model 1C) the results suggest that interest rate adjustments by the ECB are mainly and strongly driven by the output term. The coefficient of the output gap is found to be nearly twice the size of the one found for UK and more than four times greater in magnitude than the one estimated for the USA. Deviations of inflation from its target do not appear to influence the central bank decision when setting interest rates. Similarly, the ECB seems to react more to deviations of unemployment from its trend value (Model 4C) than to the inflation gap. However, the magnitude of the contemporaneous coefficient of unemployment gap $(-0.051)$ is found to be much smaller in magnitude compared to the coefficient of output gap (0.410).

Estimations based on PI and PID rules including one period lagged values (Models 2C and 5C) and two-period lagged values (Model 3C and 6C) of the independent variables show similar results to the ones found from the Taylor-type rule. The response from the ECB is mainly determined by deviations of output and/or unemployment from its trend values rather than to current deviations of inflation from its target. Although the coefficients of these lagged terms are generally found to be statistically insignificant, according to the AIC

\footnotetext{
${ }^{18}$ Model 1B against Model 3B: $x^{2}(4)=9.99$ and $p$-value $=0.041$; Model 2B against Model 3B: $x^{2}(2)=7.76$ and $p$ value $=0.021$; Model 4B against Model 6B: $x^{2}(4)=29.26$ and $p$-value $=0.000$; and Model 5B against Model 6B: $x^{2}(2)=10.40$ and $p$-value $=0.006$.
} 
criterion the PI rule seems to fit the data better when the output gap is considered in the specification $^{19}$ whereas the PID rule fits the data better when the unemployment gap is used instead.

Focusing on the PI-rule model, we observe the effect of the output gap to be greater in magnitude than the one estimated using alternative models. A closer examination, however, shows that the magnitude of the contemporaneous output gap coefficient estimated for the PI model is similar in magnitude to the one reported in the Taylor-rule model $(F$-value $=0.03$ and $p$-value $=0.862)$ but not with the cumulative effect $(0.281)$ found in the PID-rule model $(F$ value $=3.17$ and $p$-value $=0.086)$. We also find that the cumulative effect of the unemployment gap (-0.024) from the PI-rule model appears to be equal to the coefficient reported in the Taylor-rule model $(F$-value $=2.47$ and $p$-value $=0.127)$. Similarly, we find no statistically significant differences in the unemployment gap coefficient when the Taylor-rule and PI-rule models are compared with the PID model. The results are generally consistent across different models and specifications suggesting that European central bank cuts (raises) rates as the unemployment (output) gap increases, but it does not react significantly to deviations of inflation from the target.

[Table 3 about here]

\section{Summary and conclusions}

This paper followed the work by Hawkins et al. (2015) and argued that the use of the socalled Taylor rules in the operation of monetary policy can be regarded as an application of Proportional-Integral-Derivative (PID) control methods. The paper uses the PID framework to explain the interest rate policy adjustments of the Bank of England, the Federal Reserve and the European Central Bank. The analysis is based on the estimation of standard control equations, which are compared to Taylor-rule estimations, and examine how adjustments in

\footnotetext{
${ }^{19}$ Furthermore, the PI-rule model is compared to PID-rule model using the LR-test, but this model identification approach provides conflicting evidence with the AIC criterion $\left(x^{2}(2)=11.11\right.$ and $p$-value $\left.=0.004\right)$.
} 
the policy rate respond to deviations of inflation from its target rate and the state of macroeconomic activity, measured alternatively by the deviation of real GDP from its trend (potential) level and the deviation of the unemployment rate from its trend (natural) rate. Generally the results are consistent across the three models, with the PID-based rule or its subset (PI) to contribute towards the understanding of macroeconomic dynamics and improvement of the explanatory power of the Taylor-rule model.

The results for the United Kingdom suggest that adjustments in the policy rate are primarily connected with deviations of inflation from its target value and that the policy rate tends to rise when inflation is above target and fall when inflation is below target. Also, the results do point to a positive and statistically significant impact arising from output deviations but no association is found with unemployment gap. Finally, we provide evidence of partial adjustment in the policy variable. The inertia implied by the significant partial adjustment parameter presumably reflects either caution or policy smoothing on the part of the Bank of England.

For the United States, the estimates of the basic control equation identify a significant impact on the policy rate arising from deviations of output around its trend potential level and from deviations of unemployment around its trend rate. Similar to the UK, the results do provide strong evidence that the policy rate moves in response to deviations of inflation from the assumed target. This is despite the fact that the Federal Reserve is the only one of the three central banks that does not have an explicit target for inflation, although the model estimates are based on the assumption that the Federal Reserve has an implicit inflation target. In the unrestricted models for the US, the lagged dependent variable is significant, suggesting a degree of partial adjustment in the policy response.

The results for the Eurozone are also interesting. Across the various models, the results suggest that the inflation deviation term is not statistically significant, but there is 
strong evidence that the policy rate responds to output and unemployment deviations in a plausible manner. For the Eurozone models, the parameter of the lagged dependent variable is also statistically significant and its magnitude suggests a more gradual adjustment in interest rates then the Fed and BoE.

Leaving the detailed interpretation of the parameter estimates to one side, our overall interpretation of the results is that they provide strong support for the notion that monetary policy decision-making can usefully be examined within the framework of the standard PID control model. While our results are of course specific to the period of the study, they indicate that the dynamic structure proposed by the PID-rule or its PI subset commonly used in engineering is a helpful structure with which to assess the impact of inflation and macroeconomic activity on interest rate policy adjustments along with the Taylor-rule used by economists. As a final comment, we should note that the approach used here examines the impact of current and lagged values in the reaction function and future work should consider whether combining PID-rules with a form of feed-forward control would improve the model performance and provide further insight into macroeconomic policy through engineering approaches. 


\section{References}

Adam, C. Codham, D. and Girardin, E. (2005), Monetary Frameworks and Institutional Constraints: UK Monetary Policy Reactions Functions, 1985-2003, Oxford Bulletin of Economic and Statistics, 67, 417-516

Astrom, K. J. and Murray, R. D. (2008), Feedback Systems: An Introduction for Scientists and Engineers, Princeton University Press

Ball, L. and Tchaidze, R. (2002).The Fed and the New Economy, American Economic Review, Papers and Proceedings of the One Hundred Fourteenth Annual Meeting of the American Economic Association, 92(2), 108-114

Bennett S (1993), A history of control engineering 1930-1955, Peter Peregrinus Ltd., Stevenage

Carstensen, K. (2006), Estimating the ECB Policy Reaction Function ,German Economic Review, 7, 1-34

Christiano, L., Trabandt, M. and Walentin, K. (2011), DSGE models for Monetary Policy Analysis, in B. Friedman and M. Woodford (eds), Handbook of Monetary Economics, Elsevier, 3A, 285-367

Clarida, R., Gali, J. and Gertler, M. (2000), Monetary Policy Rules and Macroeconomic Stability: Evidence and some Theory, Quarterly Journal of Economics, 115, 147-80

Clemente, J., Montañes, A. and Reyes, M. (1998), Testing for a unit root in variables with a double change in the mean, Economics Letters, 59: 175-182

Goodfriend, M. (2007), How the world achieved consensus on monetary policy?, Journal of Economic Perspectives, 21(4), 47-68

Hawkins, R.J., Speakes, J. K. and Hamilton, D.E. (2015), Monetary Policy and PID Control, Journal of Economic Interaction Coordination, 10(1), 183-187

Hayo and Hofmann (2006), Comparing Monetary Policy Reaction Functions: ECB versus Bundesbank, Empirical Economics, 31(3), 645-62

House of Lords. (2005), $4^{\text {th }}$ Report of Session 2005-2006: Monetary Policy, Minutes of Evidence, Select Committee on Economic Affairs, HL Paper 78

King, M. (2012), Twenty years of Inflation Targeting, The Stamp Memorial Lecture, London School of Economics

Kobayashi, T. (2005), Optimal Monetary Policy and the Role of Hybrid Inflation-Price-Level Targets, Applied Economics, 36 2119-25

Kozicki, S. (1999), How useful are Taylor rules for monetary policy? Federal Reserve Bank of Kansas City Economic Review (2), 5-33 
Levin A, Wieland V, Williams JC (2003), The performance of forecast-based monetary policy rules under model uncertainty, American Economic Review, 93:622-645

Martin, C. and Milas, C. (2004), Modelling Monetary Policy: Inflation Targeting in Practice, Economica, 71, 209-221

Nelson, E. (2001), UK Monetary Policy 1972-1997: A Guide using Taylor Rules, CEPR Discussion Paper 2931

Orphanides, A. and Williams, J. C. (2008), Learning, Expectations Formation, and the Pitfalls of Optimal Control Monetary Policy, Journal of Monetary Economics, 55, S80-S96

Phillips, P.C.B. and Perron, P. (1988), Testing for Unit Roots in Time Series Regression, Biometrika, 75, 335-346.

Pollock, D. S. G., (2000), Trend Estimation and De-Trending via Rational Square-Wave Filters, Journal of Econometrics, Elsevier, Elsevier, 99, 2, 317-334

Shepherd, D. and Dixon, R. (2008), The Cyclical Dynamics and Volatility of Australian Output and Employment, Economic Record, 84.264, 34-39

Schmitt-Grohe, Stephanie and Martin Uribe (2007), "Optimal Simple and Implementable Monetary and Fiscal Rules," Journal of Monetary Economics, 54 (6), September, 17021725 .

Taylor, J. B. (1993), Discretion Versus Policy Rules in Practice, Carnegie-Rochester Conference Series on Public Policy, 39, 195-214

Taylor, J. B. (1999), The Robustness and Efficiency of Monetary Policy Rules as Guidance for Interest Setting by the European Central Bank, Journal of Monetary Economics, 43, 65577

Taylor, J.B. and Williams. J. C. (2011), Simple and Robust Rules for Monetary Policy, in B Friedman and M Woodford (eds), Handbook of Monetary Economics, Elsevier, 3B, 829-60.

Williams, J. C. (2011), Unconventional Monetary Policy: Lessons from the Past Three Years, FRBSF Economic Letter, $3^{\text {rd }}$ October

Williams, J. C. (2003), "Simple Rules for Monetary Policy," Federal Reserve Bank of San Francisco Economic Review, 2003

Woodford, M. (2003), Optimal Interest-Rate Smoothing, Review of Economic Studies, 70(4), 861-886.

Woodford, M. (2013), Forward Guidance by Inflation-Targeting Central Banks, CEPR Discussion Paper 9722

Zivot, E. and Andrews, K. (1992), Further Evidence On The Great Crash, The Oil Price Shock, and The Unit Root Hypothesis, Journal of Business and Economic Statistics, 10, 25170 
Table 1: UK Model Estimates using Taylor, PI and PID rules

\begin{tabular}{|c|c|c|c|c|c|c|c|c|c|c|c|c|}
\hline \multirow{2}{*}{ Model: } & \multicolumn{2}{|c|}{ Model 1A } & \multicolumn{2}{|c|}{ Model 2A } & \multicolumn{2}{|c|}{ Model 3A } & \multicolumn{2}{|c|}{ Model 4A } & \multicolumn{2}{|c|}{ Model 5A } & \multicolumn{2}{|c|}{ Model 6A } \\
\hline & \multicolumn{2}{|c|}{ Taylor } & \multicolumn{2}{|c|}{ PI Model } & \multicolumn{2}{|c|}{ PID Model } & \multicolumn{2}{|c|}{ Taylor } & \multicolumn{2}{|c|}{ PI Model } & \multicolumn{2}{|c|}{ PID Model } \\
\hline Variables & Coef. & $\begin{array}{c}\text { Newey-West } \\
\text { Std. Err. }\end{array}$ & Coef. & $\begin{array}{c}\text { Newey- } \\
\text { West Std. } \\
\text { Err. }\end{array}$ & Coef. & $\begin{array}{c}\text { Newey- } \\
\text { West Std. } \\
\text { Err. }\end{array}$ & Coef. & $\begin{array}{c}\text { Newey- } \\
\text { West Std. } \\
\text { Err. }\end{array}$ & Coef. & $\begin{array}{c}\text { Newey- } \\
\text { West Std. } \\
\text { Err. }\end{array}$ & Coef. & $\begin{array}{l}\text { Newey-West } \\
\text { Std. Err. }\end{array}$ \\
\hline$i_{t-1}$ & $0.940 * * *$ & 0.063 & $0.946 * * *$ & 0.069 & $0.949 * * *$ & 0.070 & $0.966 * * *$ & 0.079 & $0.945^{* * *}$ & 0.057 & $0.919 * * *$ & 0.050 \\
\hline$p_{t}$ & $0.164 * *$ & 0.071 & $0.173 * *$ & 0.084 & 0.167 & 0.090 & $0.152 * *$ & 0.070 & $0.128 * *$ & 0.058 & 0.119 & 0.105 \\
\hline$p_{t-1}$ & & & 0.007 & 0.077 & 0.027 & 0.076 & & & 0.024 & 0.072 & -0.019 & 0.071 \\
\hline$p_{t-2}$ & & & & & 0.019 & 0.088 & & & & & 0.010 & 0.096 \\
\hline$m_{y, t}$ & $0.223 * *$ & 0.084 & $0.245^{* *}$ & 0.102 & $0.229 * *$ & 0.102 & & & & & & \\
\hline$m_{y, t-1}$ & & & -0.043 & 0.099 & 0.044 & 0.066 & & & & & & \\
\hline$m_{y, t-2}$ & & & & & -0.111 & 0.099 & & & & & & \\
\hline$m_{u, t}$ & & & & & & & 0.002 & 0.018 & $-0.071 * * *$ & 0.019 & -0.021 & 0.016 \\
\hline$m_{u, t-1}$ & & & & & & & & & $0.078 * * *$ & 0.015 & -0.032 & 0.033 \\
\hline$m_{u, t-2}$ & & & & & & & & & & & $0.076^{*}$ & 0.022 \\
\hline constant & 0.616 & 0.310 & 0.615 & 0.396 & $0.650 *$ & 0.411 & 0.465 & 0.398 & 0.547 & 0.368 & $0.592 *$ & 0.335 \\
\hline AIC & & 5.08 & & & & & & & & & & 9.58 \\
\hline Shapiro-Wilk W test & & 0.98 & & & & & & & & & & 0.95 \\
\hline Ramsey RESET test & & 0.15 & & & & & & & & & & $.33^{*}$ \\
\hline Adjusted R-squared & & .919 & & & & & & & & & & .934 \\
\hline Observations & & 43 & & & & & & & & & & 43 \\
\hline
\end{tabular}

\section{Notes:}

***Statistically significant at the $1 \%$ level; **Statistically significant at the $5 \%$ level. *Statistically significant at the $1 \%$ level.

OLS with heteroskedasticity and autocorrelation-consistent standard errors - Based on Newey-West adjusted S.E.s Bartlett weights, truncation lag $=4$. 
Table 2: US Model Estimates using Taylor, PI and PID rules

\begin{tabular}{|c|c|c|c|c|c|c|c|c|c|c|c|c|}
\hline \multirow{3}{*}{$\begin{array}{l}\text { Model: } \\
\text { Variables }\end{array}$} & \multicolumn{2}{|c|}{ Model 1B } & \multicolumn{2}{|c|}{ Model 2B } & \multicolumn{2}{|c|}{ Model 3B } & \multicolumn{2}{|c|}{ Model 4B } & \multicolumn{2}{|c|}{ Model 5B } & \multicolumn{2}{|c|}{ Model 6B } \\
\hline & \multicolumn{2}{|c|}{ Taylor } & \multicolumn{2}{|c|}{ PI Model } & \multicolumn{2}{|c|}{ PID Model } & \multicolumn{2}{|c|}{ Taylor } & \multicolumn{2}{|c|}{ PI Model } & \multicolumn{2}{|c|}{ PID Model } \\
\hline & Coef. & $\begin{array}{c}\text { Newey- } \\
\text { West Std. } \\
\text { Err. }\end{array}$ & Coef. & $\begin{array}{c}\text { Newey- } \\
\text { West Std. } \\
\text { Err. }\end{array}$ & Coef. & $\begin{array}{l}\text { Newey- } \\
\text { West Std. } \\
\text { Err. }\end{array}$ & Coef. & $\begin{array}{l}\text { Newey- } \\
\text { West Std. } \\
\text { Err. }\end{array}$ & Coef. & $\begin{array}{l}\text { Newey- } \\
\text { West Std. } \\
\text { Err. }\end{array}$ & Coef. & $\begin{array}{c}\text { Newey- } \\
\text { West Std. } \\
\text { Err. }\end{array}$ \\
\hline$i_{t-1}$ & $0.908 * * *$ & 0.030 & $0.908 * * *$ & 0.030 & $0.922 * * *$ & 0.035 & $0.810 * * *$ & 0.030 & $0.882 * * *$ & 0.039 & $0.921 * * *$ & 0.042 \\
\hline$p_{t}$ & $0.206^{*}$ & 0.120 & $0.221 *$ & 0.132 & 0.175 & 0.109 & 0.122 & 0.103 & $0.136^{* *}$ & 0.055 & $0.091 *$ & 0.049 \\
\hline$p_{t-1}$ & & & 0.107 & 0.081 & $0.176^{* *}$ & 0.072 & & & 0.089 & 0.064 & 0.108 & 0.068 \\
\hline$p_{t-2}$ & & & & & -0.006 & 0.106 & & & & & 0.007 & 0.068 \\
\hline$m_{y, t}$ & $0.092 * *$ & 0.038 & $0.165^{*}$ & 0.096 & $0.168 *$ & 0.094 & & & & & & \\
\hline$m_{y, t-1}$ & & & -0.081 & 0.111 & 0.076 & 0.057 & & & & & & \\
\hline$m_{y, t-2}$ & & & & & $-0.182 * *$ & 0.084 & & & & & & \\
\hline$m_{u, t}$ & & & & & & & $-0.043 * * *$ & 0.008 & $-0.088 * * *$ & 0.015 & $-0.073 * * *$ & 0.012 \\
\hline$m_{u, t-1}$ & & & & & & & & & $0.061 * *$ & 0.023 & 0.013 & 0.020 \\
\hline$m_{u, t-2}$ & & & & & & & & & & & $0.042 * *$ & 0.016 \\
\hline constant & $0.518^{* *}$ & 0.196 & $0.687 * * *$ & 0.245 & $0.673 * *$ & 0.346 & $0.933 * * *$ & 0.203 & $0.767 * * *$ & 0.220 & $0.585^{* *}$ & 0.269 \\
\hline AIC & & 31 & & & & & & & & & & \\
\hline Shapiro-Wilk W test & & & & & & & & & & & & \\
\hline Ramsey RESET test & & & & & & & & & & & & \\
\hline Adjusted R-squared & & 46 & & & & & & & & & & \\
\hline Observations & & & & & & & & & & & & \\
\hline
\end{tabular}

Notes:

$* * *$ Statistically significant at the $1 \%$ level; **Statistically significant at the $5 \%$ level. *Statistically significant at the $1 \%$ level.

OLS with heteroskedasticity and autocorrelation-consistent standard errors - Based on Newey-West adjusted S.E.s Bartlett weights, truncation lag $=4$. 
Table 3: EU Model Estimates using Taylor, PI and PID rules

\begin{tabular}{|c|c|c|c|c|c|c|c|c|c|c|c|c|}
\hline \multirow{3}{*}{$\begin{array}{l}\text { Model: } \\
\text { Variables }\end{array}$} & \multirow{2}{*}{\multicolumn{2}{|c|}{$\begin{array}{c}\text { Model 1C } \\
\text { Taylor }\end{array}$}} & \multirow{2}{*}{\multicolumn{2}{|c|}{$\begin{array}{l}\text { Model 2C } \\
\text { PI Model } \\
\end{array}$}} & \multirow{2}{*}{\multicolumn{2}{|c|}{$\begin{array}{c}\text { Model 3C } \\
\text { PID Model }\end{array}$}} & \multirow{2}{*}{\multicolumn{2}{|c|}{$\begin{array}{c}\text { Model 4C } \\
\text { Taylor } \\
\end{array}$}} & \multirow{2}{*}{\multicolumn{2}{|c|}{$\begin{array}{l}\text { Model 5C } \\
\text { PI Model }\end{array}$}} & \multicolumn{2}{|c|}{ Model 6C } \\
\hline & & & & & & & & & & & \multicolumn{2}{|c|}{ PID Model } \\
\hline & Coef. & $\begin{array}{c}\text { Newey-West } \\
\text { Std. Err. }\end{array}$ & Coef. & $\begin{array}{c}\text { Newey-West } \\
\text { Std. Err. }\end{array}$ & Coef. & $\begin{array}{l}\text { Newey-West } \\
\text { Std. Err. }\end{array}$ & Coef. & $\begin{array}{l}\text { Newey-West } \\
\text { Std. Err. }\end{array}$ & Coef. & $\begin{array}{c}\text { Newey- } \\
\text { West Std. } \\
\text { Err. }\end{array}$ & Coef. & $\begin{array}{l}\text { Newey-West } \\
\text { Std. Err. }\end{array}$ \\
\hline$i_{t-1}$ & $0.645^{* * *}$ & 0.083 & $0.595 * * *$ & 0.136 & $0.762 * * *$ & 0.110 & $0.710 * * *$ & 0.146 & $0.809 * * *$ & 0.099 & $0.845^{* * *}$ & 0.120 \\
\hline$p_{t}$ & 0.073 & 0.061 & 0.097 & 0.082 & 0.038 & 0.085 & 0.006 & 0.061 & 0.097 & 0.088 & 0.068 & 0.087 \\
\hline$p_{t-1}$ & & & 0.057 & 0.091 & 0.014 & 0.097 & & & 0.144 & 0.106 & 0.112 & 0.115 \\
\hline$p_{t-2}$ & & & & & -0.094 & 0.113 & & & & & -0.010 & 0.096 \\
\hline$m_{y, t}$ & $0.410^{* * *}$ & 0.064 & $0.425 * * *$ & 0.081 & $0.369^{* * *}$ & 0.047 & & & & & & \\
\hline$m_{y, t-1}$ & & & 0.043 & 0.133 & $0.175^{* *}$ & 0.072 & & & & & & \\
\hline$m_{y, t-2}$ & & & & & $-0.263 * * *$ & 0.076 & & & & & & \\
\hline$m_{u, t}$ & & & & & & & $-0.051^{* *}$ & 0.024 & $-0.168 * * *$ & 0.028 & $-0.119 * *$ & 0.049 \\
\hline$m_{u, t-1}$ & & & & & & & & & $0.144 * * *$ & 0.033 & 0.049 & 0.078 \\
\hline$m_{u, t-2}$ & & & & & & & & & & & 0.059 & 0.038 \\
\hline constant & $1.174 * * *$ & 0.265 & $1.428 * *$ & 0.562 & 0.649 & 0.535 & $0.889 * *$ & 0.393 & $0.877 * *$ & 0.457 & 0.679 & 0.548 \\
\hline AIC & & 6.93 & & 2.58 & & .19 & & .42 & & & & -2.06 \\
\hline Shapiro-Wilk W test & & 0.52 & & .99 & & 98 & & 97 & & & & 0.97 \\
\hline Ramsey RESET test & & .981 & & .61 & & 09 & & .4 & & & & $3.90 * *$ \\
\hline Adjusted R-squared & & 0.947 & & 944 & & 60 & & 891 & & & & 0.947 \\
\hline Observations & & 35 & & 34 & & 3 & & 35 & & & & 33 \\
\hline
\end{tabular}

Notes:

$* * *$ Statistically significant at the $1 \%$ level; **Statistically significant at the $5 \%$ level. *Statistically significant at the $1 \%$ level.

OLS with heteroskedasticity and autocorrelation-consistent standard errors - Based on Newey-West adjusted S.E.s Bartlett weights, truncation lag $=4$. 